\title{
When the Window Cracks: Transparency and the Fractured Self in Depersonalisation
}

\section{Anna Ciaunica ${ }^{1,2}$ - Jane Charlton ${ }^{3} \cdot$ Harry Farmer $^{4}$}

Published online: 6 June 2020

(C) The Author(s) 2020

\begin{abstract}
There has recently been a resurgence of philosophical and scientific interest in the foundations of self-consciousness, with particular focus on its altered, anomalous forms. This paper looks at the altered forms of self-awareness in Depersonalization Disorder (DPD), a condition in which people feel detached from their self, their body and the world (Derealisation). Building upon the phenomenological distinction between reflective and pre-reflective self-consciousness, we argue that DPD may alter the transparency of basic embodied forms of pre-reflective self-consciousness, as well as the capacity to flexibly modulate and switch between the reflective and pre-reflective facets of self-awareness. Empirical evidence will be invoked in support of the idea that impaired processing of bodily signals is characteristic of the condition. We provide first-hand subjective reports describing the experience of self-detachment or fracture between an observing and an observed self. This split is compared with similar selfdetachment phenomena reported in certain Buddhist-derived meditative practices. We suggest that these alterations and changes may reveal the underlying and tacit transparency that characterises the embodied and basic pre-reflective forms of self-consciousness, in the same way that a crack in a transparent glass may indicate the presence of an unnoticed window.
\end{abstract}

Keywords self-consciousness $\cdot$ sense of self $\cdot$ depersonalisation $\cdot$ embodiment $\cdot$ meditation

Anna Ciaunica

a.ciaunica@ucl.ac.uk

Jane Charlton

jane.charlton55@gmail.com; https:/www.unrealuk.org

Harry Farmer

h.farmer@bath.ac.uk

Extended author information available on the last page of the article 


\section{Introduction}

There has been a resurgence of philosophical and scientific interest in the foundations of self-consciousness ${ }^{1}$, with particular focus on its altered, anomalous forms. This growing body of research includes a wide range of phenomena including: (i) selfexploratory practices in Buddhist and Buddhist-derived meditative practices (Garfield 2015; Dahl et al. 2015; Lindahl et al. 2017); (ii) experiences under psychedelic drugs (Carhart-Harris et al. 2012; Letheby and Gerrans 2017; Millière et al. 2018); and (iii) induced illusions (Blanke and Metzinger 2009; Lenggenhager et al. 2007). In addition, altered forms of self-consciousness have also been frequently examined in relation to clinical conditions such as: (i) schizophrenia (Parnas and Sass 2001; Fuchs 2015); (ii) psychosis (Sass and Parnas 2003); and (iii) Depersonalisation Disorder (Sierra and David 2011; Seth et al. 2012; Medford et al. 2016; Billon 2017a,b; Gerrans 2018).

In this paper we look at altered forms of self-awareness in Depersonalization Disorder (DPD henceforth), a relatively neglected condition. DPD is typically characterised by a disturbing change in the quality of subjective conscious experiences, which induces alienating feelings of detachment or estrangement from one's self, one's body and/ or one's surroundings ("derealisation") (Dugas 1898; Sierra and Berrios 1998; Sierra 2009; Sierra and David 2011; Medford et al. 2016). This profound alteration of self-awareness affects not only: (a) the low-level sensory and bodily aspects of the self (detachment from one's body or body parts); but also (b) the experiential aspects (detachment from one's subjective feelings and emotions); and (c) high-level, cognitive and narrative aspects -disconnection from one's personal stories, memories, thoughts and future plans), often described by DPD patients as a loss of the narrative flow or "plot" of one's life (Ciaunica and Charlton 2018). Importantly, unlike other dissociative self-disorders such as psychosis, schizophrenia (Stanghellini 2009) or Cotard's delusion (Gerrans 2000), and despite the dramatic nature of their 'estrangement' and self-detachment, DPD patients are aware that these are subjective phenomena rather than the objective reality.

In this paper we build upon the phenomenological distinction between reflective and pre-reflective self-consciousness (Gallagher and Zahavi 2005), and consider both (a) the I- and body-as-subject and (b) the I- and body-as-object of an experience (Legrand 2006), in order to argue that DPD may alter the transparency of basic embodied forms of self-consciousness, as well as the capacity to flexibly modulate and switch between these two facets (a) and (b) of self-experiences.

Transparency - as we will see in the next section in more detail -is an interesting and peculiar property of our experiences and can be metaphorically understood as looking through a window. For example: a perfectly clear and transparent window glass or sliding door can give us the illusion of an unmediated access to a landscape. The landscape seems present and reachable, paradoxically because the glass of the is transparent, invisible and taken for granted. It is there without us being aware of it. However, in some cases, as we will see later, one can become aware of the existence of

\footnotetext{
${ }^{1}$ Throughout this paper we will use the terms "self-consciousness" and "self-awareness" interchangeably, although it could be argued that self-awareness refers to low-level self-related sensory processing; while selfconsciousness seems to evoke higher-level self-related processing. This distinction, however, need not concern us here.
} 
the invisible and mediating transparency of the window itself, so to speak. Indeed, suppose there is a crack in the pane of glass. Two important observations emerge here. a) First, we become aware of the cracked window itself as a visible observable entity: we realize that there was something there without us being originally aware of its presence. b) Second, while the cracks in the window's glass make the latter visible, they also make our access to the landscape more 'opaque' or 'mediated' (Fuchs 2005). We may still perceive the outer landscape through the cracked window, but its clarity is hindered. Now we are aware that something stands in the way and disrupts our full immersion into the reality of the landscape.

The key idea is that DPD, profoundly alters the embodied pre-reflective roots of selfawareness, and may reveals its tacit, transparent and taken for granted presence in our everyday life, in the same way that a crack in a transparent glass reveals the presence of an unnoticed window. These alterations increase the incidence of compensatory hyper-reflective mentalistic forms of self-awareness, with consequent self-opacity, and lack of immersiveness into the world (Fuchs 2005), which is often described by DPD patients via metaphors such as being 'trapped' inside one's head (mind) and outside one's body, 'living in a bubble' or being 'a floating head' disconnected from the body (**Author, Simeon and Abugel 2006).

We unpack these ideas below and structure this paper as follows: in Section 2 we define the key notions of reflective and pre-reflective self-consciousness, as well as transparency, before outlining the bodily roots of pre-reflective forms of selfhood. Then we move, in Section 3, to introduce the case of Depersonalisation Disorder and provide empirical evidence supporting a link between disruptions of self-awareness and impaired bodily processing in this condition. Section 4 brings in first-hand subjective reports describing the experience of a self-detachment as a 'fracture' between an observing and an observed self. We suggest that disruptions of the transparent, embodied and pre-reflective sense of self may be at work in DPD, impairing the ability to navigate flexibly between the I- and body-assubject and (b) the I- and body-as-object of an experience. The increasing weight put on the latter over the former leads to the prevalence of hyper-reflective mentalistic forms of selfawareness, and consequent to self-opacity and feelings of 'living in a bubble', disconnected from one's self, body and the world.

The final Section 5 briefly invokes similar self-detachment experiences reported in some Buddhist-derived meditative practices. We suggest that changes in self-experiences induced by these contemplative techniques may reveal the underlying and tacit transparency characterising embodied pre-reflective forms of self-consciousness. We outline the key role played by bodily awareness, and specifically by touch, in modulating self-experiences in both meditation and depersonalisation. The paper concludes with some speculative remarks about future directions of research, suggested by our hypotheses, that may prove useful for developping potential therapeutic and interventional tools for alleviating feelings of depersonalisation.

\section{Self-consciousness, Transparency and the Sense of Self}

Defining self-consciousness has long been a preoccupation of philosophers and scientists alike, across all traditions and disciplines. Specifically, the question of what, if anything, makes the 'self' a unifying phenomenon has attracted a considerable number of recent empirical studies and theoretical accounts (Gallagher 2000; Metzinger 2003; Zahavi 2005; Blanke and Metzinger 2009). The task is challenging, given that the 
notion of 'self' covers a set of complex and multifaceted aspects of conscious experiences, ranging from low-level bodily, to high-level cognitive or narrative aspects, which has been described as a 'pattern theory of the self' (Gallagher 2013). While a detailed review of research on self-awareness and its alterations lies beyond the scope of this paper, a minimal, working definition is needed, in order to better grasp what is altered in the self-experiences of people with DPD.

Let us start with an example: suppose I see a tree in the garden. One intuitive starting point is to introspect what I am experiencing while seeing the tree. In other words, I attempt to observe what is happening 'inside me' while I am having this experience. I can find joy or sadness, perhaps. I may take a picture of myself and reflect aloud that 'this is me' or 'this is my body' or 'this is me, next to a tree'. Self-introspection of one's inner experiences, together with self-recognition and self-identification as an individual, distinct from the world and others, are typically considered key landmarks of self-consciousness and its emergence in early childhood (cf. Lewis 2003: 281-282). This form of self-consciousness, which occurs, for instance, whenever one reflectively observes or introspects one's on-going experiences or during explicit self-recognition of one's face in the mirror, is typically called higher-order or reflective self-consciousness (Carruthers 1996; Rosenthal 1997). Note importantly here that I take myself as an object of experience/introspection/reflection. Indeed, the subject-object axis constitutes a paradigmatic structure of a perceptual experience, whereby the experiencing subject relates to, and is directed at, an intentional object in the world (the tree, my body, my thoughts).

However, it has been proposed that there is another, more primary form, i.e. prereflective self-consciousness which: (i) does not stand in a transitive ${ }^{2}$ relation to the state of which it is aware; and (ii) is in place before we do any mentalistic and introspective reflecting on our experiences (Gallagher and Zahavi 2015). This basic form is tacitly present whenever one is experiencing something, and does not involve any kind of higher-order monitoring (Strawson 1999; Legrand 2006; Kriegel 2009; Zahavi 2014; Zahavi and Gallagher 2010). Rather, there is a sense in which the 'I' or the 'self' in self-consciousness should be conceived as a fundamentally first-person subject of an experience: "being presented with something necessarily involves being pre-reflectively and pre-conceptually aware of being the subject to whom something is presented" (Nida-Rümelin 2017: 66). As Sartre famously put the point, this form of consciousness is "a consciousness has no need at all of a reflecting [higher-order] consciousness in order to be conscious of itself. It simply does not posit itself as an object." (Sartre, 193629 [1957, 45], our italics).

This view echoes the phenomenological distinction between (1) the body I prereflectively live through as a subject (i.e. the subject-body or the body-as-subject, "Leib"); and (2) the physical body that I can observe and which can be observed by others (i.e. the object-body or the body-as-object, "Körper") (Husserl 1973:57; Merleau-Ponty 1945). For example, an anorexic person may see her subjective body ("leib") as extremely fat, while her objective body ("körper") is actually skinny. A similar distinction was famously proposed by W. James (1890) between 'I' and 'me', whereby the latter may map onto the self-as-object, while the former the self-as-subject (see Wozniak 2018). Wittgenstein (1958) is yet another

\footnotetext{
${ }^{2}$ One can distinguish between a) the transitive form (being conscious of something); and b) the intransitive form (being conscious simpliciter - rather than non-conscious). For example, I can be conscious of my breath; or I can consciously breath (being alive rather than dead).
} 
influential thinker who proposed a distinction between I-as-subject and I-as-object of an experience (see Longuenesse 2017).

Interestingly, several theorists have proposed that despite the fact that we may subjectively feel that we are in immediate contact with our self and the world, our experiences are in fact mediated via certain mental states which have the property of being 'transparent'. The notion of 'transparency' has been traditionally spelled out in different ways by different theorists (Moore 1903; Harmann 1990; Tye 1999). For example, Metzinger (2003) influentially argued that the experience of being someone (the 'I'/'me') arise through the processing of a transparent phenomenal self-model (PSM) which itself can in principle be explained in terms of representational brain processes. It is the co-representation of (a) the self and (b) the intentionality relation, i.e. directedness towards objects of attention (e.g. a tree) which produces the experience of a strong first-person perspective that makes consciousness subjective. Importantly, transparency leads to the identification of the system with the content of its PSM. While we typically have access only to the representation's intentional content (something in the world which it is about), without noticing its non-intentional carrier properties, the actual process of constructing inner representations can, however, become available to our introspective attention. Whenever we consciously direct our attention introspectively inwards, so to speak, the transparent processing of mental representations (typically taken for granted and hence 'invisible') becomes 'opaque', that is, 'visible' and available to our attention (cf. the window metaphor described in Introduction).

A detailed discussion of these distinctions and approaches lies beyond the scope of our paper. For our purposes, we will build upon the phenomenological insight that any experience directed towards an object implies a pre-reflective self-awareness that makes my experiences immediately and tacitly given as mine (Zahavi 2005). This first-personal givenness of all our experiences may be regarded as general medium through which our bodily sensations, movements and thoughts are integrated and articulated as a unitary whole: a "basic and foundational medium (...) called sense of self or "mineness"' (Fuchs 2015: 325).

Importantly, the practical immersion of the self in the world is mediated by the body, an organism embedded in a wider physical and social environment (Merleau-Ponty 1964; Gallagher 2000; de Jaegher and di Paolo 2007). This emphasis on the embodied roots of the selfhood is echoed within neuroscience research (Panksepp 1998; Northoff and Panksepp 2008; Ciaunica 2016, 2019; Seth and Tsakiris 2018; Ciaunica and Crucianelli 2019). As Damasio puts it: "the earliest origins of the self are to be found in the totality of those brain mechanisms that constantly and unconsciously ensure that the states of the body vary within the small range of relative stability that is necessary for survival" (2000:36). In this view, the function of perceptual experiences is ultimately geared towards self-preservation, by maintaining and regulating the physiological needs and integrity of the organism (the human body). More radically, one can argue that we do not perceive the world as it is, but as it is useful for us to perceive it, for our self and our survival (Seth and Tsakiris 2018). To put it provocatively, perception and experiences are inherently "selfish" (Ciaunica and Crucianelli 2019). That is, whenever we experience anything, self-related interests (information relevant to self-preservation) are automatically "smuggled in" and guide both our perception and actions. My sense of self is thus intimately anchored in my body as the subjective centre of gravity of all my sensations, experiences, emotions, memories and thoughts, and which is distinct from the rest of the world. 
To sum up so far: in daily life and under normal circumstances, there is a basic, embodied and pre-reflective sense of self or mineness which is 'transparent', i.e. implicit, taken for granted and does not require our explicit attention ${ }^{3}$. This property enables our subjective feeling of being fully immersed in the world. With these elements in our pocket, we can take a closer look at the case of Depersonalisation, in order to argue that alterations of the transparency of embodied pre-reflective sense of self may be at work in this condition.

\section{3 'Trapped in the Mind and Outside the body': the Fractured Self in Depersonalisation}

To understand depersonalisation, one potentially fruitful strategy is to start with a firstpersonal subjective self-report. Here Jane C. (one of the authors of this paper), who has a diagnosis of DPD, describes here how she felt after smoking cannabis for the second time in her life, in France on the 29th of March 2002:

"My perception felt as though it had been drawn back inside my head, almost as though I was looking at the world from the back of my head, and could see the back of my own eye sockets. (...) Essentially, it felt like there was a divorce or fracture between the world and me so that although my body was still in the world, my mind was only an observer. (...) These were all sensations whose existence I didn't even knew one hour before. (...) There followed some hours of seeking reassurance from those around me, wanting to be in physical contact with them and talk to them constantly to check that I still existed, until, exhausted, I slept, in the hope that it would pass overnight. It didn't." (**Jane C.).

It is typical for DPD experiences to be characterised as a 'divorce' or 'fracture' between an observing and observed self, which may lead to alienating feelings of being an automaton, a machine (Sierra 2009) or a robot-like thing (Simeon and Abugel 2006): "I feel like a robot, like I am listening to someone else talking, like I am looking at myself from the outside, but it is not another voice or body - it is mine, it is me, it just doesn't feel like it." (Baker et al. 2003). More dramatically, this can trigger feelings of deadness, of being a zombie (Sierra 2009, 51) or of being walking dead (Simeon and Abugel 2006:24): "it almost feels like I have died, but no one has thought to tell me. So, I'm left living in a shell that I don't recognize anymore" (Sierra 2009:27). Or: "I am in a constant state of grief. I do feel as if I'm grieving for my own death. Even if I seem to be around to witness it." (Jane C.).

Recent epidemiological surveys suggest that transient episodes of depersonalisation are common among the general population, with an estimated lifetime prevalence of between 26-74\% (Hunter et al. 2004; Michal et al. 2009). The experience of depersonalisation can, however, become a chronic condition, resulting is a diagnosis of Depersonalisation/Derealisation Disorder (DPD; American Psychiatric Association, 2013), the prevalence of which is estimated to be between 1-2\% (Tibubos et al. 2017). A factor analysis on the 29 items of the Cambridge Depersonalisation Scale (CDS-29; Sierra et al., 2005; Sierra \& Berrios, 2000) has suggested that, rather than being a

\footnotetext{
${ }^{3}$ We are grateful to an anonymous reviewer for clarification of this point.

${ }^{4}$ It is worth noticing that 18 years later $* *$ Author continues to struggle with such feelings.
} 
unitary symptom, experiences of depersonalisation should be thought of as a syndrome with four different dimensions: (1) anomalous body experiences, including feelings of disembodiment, lack of body ownership and lack of agency; (2) emotional numbing; (3) anomalous subjective recall, particularly when remembering autobiographical events; and (4) alienation from surroundings, i.e. derealisation.

While the experiential characteristics of depersonalisation have been reported for over a century (Sierra and Berrios 1997), the cognitive and neural mechanisms underlying the condition are still not well understood. For example, Hunter and colleagues (2003) drew upon evidence for a link between cases of DPD and anxiety (Baker et al. 2003; Hoyer et al. 2013; Hunter et al. 2004) and trauma (Simeon 2004; Tibubos et al. 2017). They argued that, while transient dissociative experiences may represent a normal adaptive response to high stress situations, chronic depersonalisation resulting in DPD is caused by a catastrophic appraisal of those experiences, leading to increased anxiety and stress, which in turn drive an increase in the frequency and intensity of depersonalisation. As one patient with $\mathrm{DPD}^{5}$ nicely express it, it is as if the brain creates an 'experiential airbag' which automatically inflates as soon as there is a risk of being crushed by an extreme danger (be it physical or psychological). In DPD, the protective experiential airbag seems to remain inflated, and one remains 'stuck' outside one's own self, disconnected from one's own experiences, bodily feelings and thoughts; and thereby isolated from the world.

While a comprehensive account of the underlying mechanisms of DPD has yet to be developed, recent work in philosophy and psychopathology suggests that there may be an intrinsic link between disruptions of bodily self-awareness and consequent feelings of self-detachment, not only in dissociative conditions such as schizophrenia (Parnas \& Sass 2001; Fuchs 2015) but also in DPD (Billon 2016; Fuchs 2015; Gerrans 2018; ** Farmer et al. submitted).

Empirical support for the role of impaired processing of bodily signals has come from studies that demonstrate disrupted physiological response in patients with DPD compared to healthy participants (Dewe et al. 2018; Owens et al. 2015; Sierra et al. 2002). Patients suffering from DPD have been found to have differential activity (compared to controls) in regions that underlie somatic processing, such as the anterior insular cortex (AIC), anterior cingulate cortex (ACC), and orbital gyrus (Lemche et al. 2013; Medford et al. 2016). There is also evidence for impaired processing in the vestibular system (Jáuregui Renaud 2015), which is responsible for providing information about the body's position in space (Ferrè and Haggard 2016). Moreover, a recent study found altered visuo-tactile self-related integration in people with high levels of depersonalisation traits (Farmer et al., under review). Several functional neuroimaging studies (De Andrade et al. 2016; Lemche et al. 2007; Medford et al. 2016) have also found evidence for increased activation of the dorsolateral prefrontal cortex (DLPFC), a region involved in attention and cognitive control (Compton et al. 2003), during emotional processing by people with DPD, consistent with subjective reports of over-scrutinization and hyper-reflexivity phenomenon in DPD. In line with this, some studies have also found evidence for both increased DLPFC volume (Daniels et al. 2015) and increased connectivity between the DLPFC and areas that

\footnotetext{
${ }^{5}$ We are indebted to Sarah Lawrie, for sharing her depersonalization experiences and for coining the "experiential airbag" metaphor.
} 
process emotion (Sierk et al. 2018) in patients with DPD. Such findings lend support to the idea that feelings of emotional numbness that occur during depersonalisation may be caused by top-down suppression of emotional responses.

Recent accounts of depersonalisation experiences have drawn on Predictive Processing $^{6}$ theoretical frameworks (Friston 2005; Clark 2013; Hohwy 2014) to argue that the loss of "mineness" experienced during depersonalisation is related to the abnormal processing of interoceptive information (i.e. information about bodily states such as hunger, thirst, pain) (Gerrans, 2018; Seth et al. 2011; Seth and Tsakiris 2018). According to the predictive processing account, impairments in the generation of prediction error signals from interoceptive regions mean that those people experiencing depersonalisation are unable to properly calibrate their predicted and actual bodily experiences. This mismatch leads to a suppression of interoceptive signals, which in turn produces the feelings of disconnection from self and world and emotional numbing that characterise depersonalisation.

The next section focuses on the subjective feeling of a fracture between an observing and observed self which seems to accentuate the feelings of being 'trapped' inside one's mind $^{7}$ and outside one's body. Specifically, we advocate the feelings of a fractured or divorced self in DPD through the lens of the distinction between the (i) I- and body-assubject and (ii) the I- and body-as-object of an experience (as introduced in Section 1). The key proposal is that DPD disrupts not only the transparency of the embodied prereflective sense of self, but also the ability to switch flexibly and thus navigate between these two forms of self-awareness. We turn to this discussion now.

\section{4 'Living in a Bubble': Opacity and Self-Objectification in Depersonalisation}

A very common complaint amongst people suffering from depersonalisation involves the lack of a certain experiential self-related feature. Billon notes that this feature has been variously described by patients as: a "feeling of 'I", the "experience of 'me' (Simeon and Abugel 2006, 143)"; the "feeling of myself (Janet and Raymond 1898 73)"; or as the "awareness of myself (Krishaber (1873, 171) and Janet (1903a, 324)" (Billon 2016; $2017)^{8}$. For example, after receiving a painful stimulus on her hand, a patient of Janet's, with depersonalized, once said: "It was painful and my arm felt like withdrawing, but it was not a genuine pain" (Janet, 1928: 65-6, quoted in Billon, 2017, italics by Billon).

There are several points worth noting from this self-report. (1) First, the person promptly and adaptively withdraws her arm, in response to pain, to avoid the harmful

\footnotetext{
${ }^{6}$ PP models treat the 'self' as a hypothesis (or prior) within the brain's hierarchical generative models, which try to maximize evidence for the organism's existence, by minimizing prediction error (by updating beliefs or by acting on the world). These approaches are proposed to account for the 'centeredness' of generative models onto the 'self', and to explain why higher levels of the hierarchical model of the self will be increasingly abstract, complex and invariant, and thus less likely to be subject to any updating by prediction error (Limanowski and Friston 2018). Importantly, this idea of a hierarchy of 'self' priors within the brain's overarching model of the self supports the philosophical idea of a (lower level) non-conscious and bodily base for higher forms of self-consciousness (Gallagher 2000).

${ }^{7}$ Interestingly, patients with DPD often express this feeling by drawing a little character, a sort of 'homunculus', that is watching the world from behind one's eyes, sitting in one's head.

${ }^{8}$ But see also Bermudez 2017 for a critical discussion of the idea that a sense of mineness is lacking.
} 
event. This suggests that while the experiential subjective dimension seems to be disrupted ("this pain is not felt like being mine"), the low-level self-related sensory processing remains intact ("I nonetheless withdraw $m y$ arm in order to selfishly protect it from harm"). (2) Second, the "pain" is experienced as non-genuine, or fake, as if something is lacking that would make it truly real. Arguably, what is missing is the subjective first-personal sense of "mineness" (see Billon, 2017) which gives an affective colour to one's experiences. (3) Finally, there appears to be a 'divorce' or split in the subjective character of the patient's experience: the self and body seem to be experienced not from a first- but from a third person, objectifying perspective. Perceptual events are experienced anonymously: the person may feel something like "there is an arm-withdrawing event" as opposed to "I am withdrawing my arm".

These observations point to a stance of self-objectification. As Fuchs (2005) pointed out in his examination of self-disturbances in schizophrenia, alterations in the basic, embodied and tacit sense of self or 'mineness' (i.e. the I- and body-assubject of an experience) may lead to self-objectification and enhanced incidence of hyper-reflexivity (i.e. the I- and body-as-object of an experience) (see also Krueger 2018). To illustrate this idea, consider again our earlier example of perceiving a tree. While I can, say, observe and grasp the tree's leaves, (I can see them, touch them, smell them), the very subjective act of "my perceiving the tree" seems ungraspable. With growing self-objectification however, the very "act of my perceiving" may come into awareness, disrupting its underlying transparency. The resulting selfopacity alters the ability to affect and to be affected (i.e. to belong, to relate to a wider world) is similarly changed. Consequently, "the world ceases to matter, people and events are not salient anymore. With this, the world ceases to move and affect one through one's body" (Colombetti \& Ratcliffe, 2012: 148). This alienating and distressing phenomenon is often and strikingly reported by DPD patients via metaphors such as 'having a pane of glass' or 'veil' interposed between one's self, body and the world, or "living like in a fog", "living in a bubble", "feeling surrounded by an invisible wall" (Simeon and Abugel 2006; Ciaunica and Charlton 2018). Indeed, DPD patients relentlessly over-scrutinize their inner experiences, seeking to 'retrieve' their former, familiar sense of self. This constant inner self-checking may trigger the distressing feelings of being trapped in their head/mind, disconnecting the person from their body and the world.

More dramatically, this disconnection may lead to alienating feelings of deadness: "there is an overriding feeling that regardless of my ability to function, I was not living any longer, and so there really was little point in the exercise. Functioning and existing are not the same as living, I learned. Incredible as it sounds, your brain is capable of dividing the two (...) I'm conscious, even as I write this, that I must have a functioning inner life; one which is capable of articulating this experience. But the capacity to knit it into any kind of meaningful narrative that I occupy and own is missing. And that absence for some reason seems to be critical to my feeling as though I am alive" (Jane C.).

This self-report can be viewed through the phenomenological distinction proposed by Husserl between (i) the intransitive 'living', 'being alive' or 'functioning' ('Leben'), and (ii) the transitive 'living through' or 'experiencing' ('Erleben'). The first seems to be a necessary but not a sufficient condition for the emergence of both a sense of self and sense of realness, or aliveness. Indeed, while I need an objectively functioning body ('Körper') in order to be alive, I also need a subjectively lived body ('Leib') in 
order to feel alive: "As though all the constituent parts of me were still working, but an essential element of my self, of my person, was missing. Something vital" (Jane C.).

Two key ideas are suggested here. (1) Firstly, the vital element that has gone 'missing' or is altered in DPD patients' experiential life may be the transparency of their basic embodied pre-reflective sense of self. (2) Secondly, these alterations impair the ability that we typically have to flexibly connect and switch between the two aspects of the bodily self (i.e. the I- and body-as-subject; and the I- and body-as-object of an experience). Consequently, DPD patients may feel like third-person onlookers (rather than first-person subjects) of their own experiences, which accentuates their observational stances of an I- and body-as-object of experience. This fracture in self-awareness may be accompanied, as we saw earlier, by a feeling of being drawn back inside one's head and perceiving the world from 'backstage', so to speak (e.g. "seeing from the back of my own eye sockets").

Interestingly, a very similar phenomenon, namely a sensation of 'divorce' between a watching and a watched self has been widely reported in certain Buddhist-based contemplative practices, such as meditation. Consider the following self-report: "The first thing I noticed was a slight change in my vision. The change was like a camera lens zooming out, a pulling back. I had the sensation that instead of looking from the front of my head I was looking from behind, through my eyes. (...) It was very much a feeling of "watching" (Castillo, 1990:163). In the remainder of this paper we put forward the hypothesis that both DPD alterations and Buddhist-based meditative changes in one's sense of self play a role in revealing the underlying transparency of basic, embodied forms of self-awareness, which typically go unnoticed and are taken for granted, in our everyday life.

\section{When the window cracks: the transparent bodily roots of the sense of self}

Recent decades have witnessed an increased interest in exploring contemplative insights from Eastern traditions and importing them into the Western world, although these have been, for the most part, adapted to fit Western societies' intellectual and cultural tendencies. Many of these contemplative practices - spanning different cultures and spiritual frameworks - have in common specific techniques of mental training, such as meditation. Meditation typically refers to a set of practices that "self-regulate the body and mind, thereby affecting mental events by engaging a specific attentional set. These practices are a subset of those used to induce relaxation or altered states such as hypnosis, progressive relaxation, and trance-induction techniques (Vaitl et al. 2005)" (Cahn and Polich 2006:180).

Contemplative techniques come in different flavours ${ }^{9}$, with various psychological effects (Sedlmeier et al. 2012). Providing a detailed review of the changes in self-

\footnotetext{
${ }^{9}$ For example, "focused attention" meditation aims at maintaining one's attention to a particular object or bodily sensation (typically the breath). "Open monitoring" meditation aims to elicit a non-judgemental, nonselective awareness of the present moment, as it unfolds, while "loving-kindness and compassionate" meditation cultivates compassion towards oneself and others. "Mantra recitation" - a form of focused attention meditation - involves the repetition of a sound, word or sentence. While focused meditation attempts to fixate the mind in a "still" position, "mindfulness" is a contemplative technique of non-reactively taking notice of whatever comes to the mind, by cultivating "bare attention" (Schwarz \& Clark, 2006). The meditator becomes an "onlooker" or "neutral observer" of her own stream of consciousness. Mindfulness can be thus seen as a sophisticated and complex form of introspection which can be used to study one's mind (Thompson, 2006).
} 
awareness that meditation induces lies beyond the scope of this paper (see Albahari 2010; Dahl et al. 2015; Lindahl and Britton 2019). In what follows we will confine our focus to one particular aspect that these induced changes seem to share with DPD, namely the experience of a change or a 'detachment' from how we normally perceive ourselves, and how we relate to our ordinary sense of self. In modifying the familiar way in which one consciously perceives oneself and the world, one "leaves behind" first and foremost one's former self (or one's ego).

For example, one core aspect of famous the doctrine of 'no-self' or 'not-self' (anattā) is that our ordinary experiences rely on the common and erroneous assumption that there is a substantial 'self' or 'subject' behind the psychophysical processes that underlie our conscious awareness. This assumption is the main source of human suffering. Now, the metaphysical question of whether the self is illusionary or of a (non)-substantial nature is a complex and difficult matter, which need not concern us (see Albahari 2010; Fink 2012; Sidertis et al. 2011 for an overview). Rather, our focus is on what people feel about their changed 'self', and not on what that self ultimately is.

But before we go further, it is important to make a brief detour and recall our initial distinction between the I- and body-as-subject and the I- and body-as-object of an experience. As we saw in the introductory section, the subject-object relation is the paradigmatic case of the structure of a perceptual awareness, whereby the experiencing subject relates to and is directed at an object in the world ${ }^{10}$. In our earlier example of my seeing a tree, it is customary to contrast a subjective 'inner' phenomenon (my conscious awareness of the tree) with an 'outer' phenomenon objectively existing in the world (the tree itself). I can also take my 'inner' self-experiences as an object of introspection or observation (e.g. I can observe my own sadness). I can also recognize myself in a mirror, for example, as a physical body/object in the world with certain characteristics (e.g. I have green eyes).

However, an alternative view is to stress that the distinction between inner and outer phenomena is made within the realm of objects, and should not be conflated with a distinction between consciousness and objects. Rather, in line with the Sartrian view evoked in Section 2, the self-presentation of consciousness, in its pre-reflective form, should not be regarded as an extra layer added to the on-going experience. 'I' does not pose itself as an object; rather it constitutes the very mode of being of the experience: "This self-consciousness we ought to consider not as a new consciousness, but as the only mode of existence which is possible for a consciousness of something" (Sartre 1943, 20 [1956, liv] ${ }^{11}$. This view seems to echo some Buddhist approaches, according to which there is a type of self-presentation that "does not consist in any objects at all, be they 'internal' or 'external', for 'the Self is neither within nor without' (Ramana Maharshi, in Sastri 1997: 27" (quoted by Fasching 2008: 466). In this view, the meditative process is not a "withdrawal from the presence of the world into some 'inner sphere', but a movement into this very presence" (Fasching 2008: 468-9). In other words, it reveals the fundamental "I-I" structure (i.e. the "I" without "me" of any conscious experience, that is, pure subjectivity).

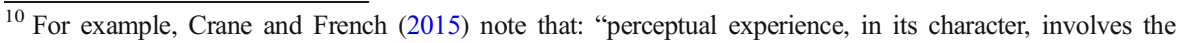
presentation of ordinary mind-independent objects to a subject, and such objects are experienced as present or there, such that the character of experience is immediately responsive to the character of its objects."

${ }^{11}$ For Sartre, "a consciousness has no need at all of a reflecting [higher-order] consciousness in order to be conscious of itself. It simply does not posit itself as an object.” (Sartre, 1936, 29 [1957, 45]).
} 
Furthermore, one can thus distinguish between at least two forms of 'self-consciousness', namely: (1) self-identification with a certain configuration of what one experiences, which includes typical forms of self-recognition (e.g. 'those green eyes seen in a mirror are mine') and self-introspection (e.g. 'that sadness I feel is mine'). These are forms of an I-as-object ('I-me') experiences; and (2) "the self-presence of experiencing itself' (Fasching 2008:464, our italics) which we can see as a basic, underlying prereflective form of self-consciousness (the I-as-subject or 'I-I' experiences). Fasching suggests - and we are inclined to follow him on this point - that the ultimate aim of (at least certain forms of) meditation is to inhibit (1) in order to clear the way for the "unveiling" or revealing of (2), which "brings to light (and constitutes) our being as subjectivity" (Fasching, 2008:464; see also Lutz et al. 2008).

As we emphasised earlier, contemplative techniques are based on different traditions and are subject to various interpretations of self-awareness ${ }^{12}$. Moreover, the oral transmission of these traditions makes the elucidation of their effects particularly challenging. Here we retain the idea that in the process of meditative practices, "one ceases to be actively occupied with the objects of consciousness in order to become conscious of consciousness itself (which usually remains 'hidden' behind what it is conscious of)" (Fasching, 2008:464, our italics). Interestingly, this idea echoes the phenomenological approach which take subjectivity not as on object to be described, but as a medium through which the world may manifest itself (Fuchs 2010). Paradoxically, it is precisely through the process of "letting go" of the self that one's "pure" subjectivity is revealed. By undergoing this type of self-detachment, "one experiences oneself non-observationally as the observing itself, as 'pure seeing' - i.e. as the taking place of manifestation (...). One simply lets what is there be there and is aware of oneself as this very taking place of being-there, which is the fundamental dimension of subjectivity" (Fasching 2008: 470).

This approach resonates with the phenomenological idea that the subjective experience itself cannot be located within a purely mental 'inner realm' (Zahavi, 1999), isolated and disconnected from the 'outer' body and its environment. Rather the "consciousness of oneself as an immediate subject of experience" (Gallagher, 2000:15) is fundamentally and tacitly anchored to one's body. As outlined earlier, there is sense in which basic bodily processing - such as homeostatic self-regulation - is fundamentally geared towards self-preservation, even when the ordinary and familiar sense of self is consciously reported as being changed, 'dissolved' or 'lost' ${ }^{13}$. The embodied component of pre-reflective self-awareness remains tacitly and 'transparently' present in the background (Limanowski and Friston 2018).

For example, in their extensive discussion of the phenomenology of self-experiences in one highly trained meditator, Ataria et al. (2015) reported that while the process of 'losing' the sense of self typically starts with a sense of self-expansion, it usually ends

\footnotetext{
${ }^{12}$ For example, one can roughly distinguish between (a) reflectionist or other-illumination (paraprakasa) theories, and (b) reflexivist or self-illumination (svaprakasa) theories (see MacKenzie, 2008:247). According to (a) reflectionist theories, self-awareness is the product of a second-order awareness taking a distinct, firstorder awareness as its intentional object. According to (b) reflexivist theories, the subject, by virtue of being aware of an object, is simultaneously and intrinsically (pre-reflectively one might say) aware of his or her own experience.

${ }^{13}$ To put it provocatively: the only and unique occasion when one effectively loses one's self is when one's (living and lived) body becomes a corpse (i.e. death).
} 
with a stage in which the sense of self and self-other boundaries disappears altogether. However - and this is a crucial point - "even when lacking a sense of boundary, some basic bodily feelings and a very liquid touching/being-touched structure continue to exist" (Ataria et al., 2015:145, our italics). In the practitioner's own words: "I am not dead; there is a kind of very light sense of body in this experience" (Ataria et al., 2015, Supplementary Material, quoted in Millière et al., 2018, our italics). Similarly, even "when [the sense of boundaries] disappears, a minimal level of dynamic proprioception continues to exist: there remains a sense that there is body without any experience of a [sense of boundaries]" (Dor-Ziderman, et al., 2016:3, our italics).

Interestingly, what seems to be difficult to eliminate completely is the experience of touch, or as they call it, following the seminal work of Merleau-Ponty (1962) "the touching/touched structure and one's bodily feelings" (Ataria, et al., 2015:133). There is emerging awareness in the contemporary study of self-consciousness that while perceptual awareness has been traditionally characterised within the unimodal frame of visual perception, conscious experiences are fundamentally multimodal in nature (Faivre, et al., 2017). In particular, similarly drawing on Merleau-Ponty (1962), several theorists have pointed to the crucial role of proximal senses such as touch and interoception in shaping self-awareness in early life and beyond (Ciaunica \& Fotopoulou, 2017; Fotopoulou \& Tsakiris, 2017; Ciaunica \& Crucianelli, 2019). Indeed, if we consider the emergence of embodied selfhood and self-experiences from a dynamic, developmental and ecological perspective, it is touch and interoception (not vision) which is the first of our senses to develop, proving us thereby with our most basic means of perceiving and 'meeting' the world (see Gallace \& Spence, 2010; Farmer \& Tsakiris, 2012 for reviews). A detailed discussion of the primacy of tactile over visual perception in constituting conscious experiences is beyond the scope of this discussion, meriting a dedicated paper.

It is, however, striking that when dissociative experiences become overwhelming, some DPD individuals use worldly engagements via proximal senses (such as touch and olfaction) as compensatory strategies. For example, individuals may: compulsively touch their own faces in a mirror; constantly touch objects, in order to check where their limbs begin or end; seek physical contact with close others, in order to keep track of their own body in space and gain affective reassurance: use sensory overstimulation (e.g. olfactory, perfume shots) to reconnect with their bodily, sensing self ${ }^{14}$.

Two main theses emerge from our discussion so far. (1) Firstly, DPD may alter the transparency of I- and body-as-subject aspect of experiences, and thereby increase the objectifying observational stance of the I- and body-as-object of experiences. This could explain why DPD individuals report feelings of being an automaton, a robot, or a machine, as if they were mere objects in the world, manoeuvred by a self which is disconnected from their one's body, and is 'trapped' in one's mind (head).

(2) Secondly, (some) meditative practices appear to modulate the transparency of Iand body-as-subject of experiences, by training one to 'let go' and detach oneself from one's ordinary observational self. Becoming self-aware in this elevated sense may lead people to reach a non-observational level of experiencing as 'pure subjectivity' (as

\footnotetext{
$14 * *$ Author is grateful to the DPD peer support group (London) for sharing these examples of their lived experience. This group has established a charity - Unreal - to raise awareness of DPD, which is a relatively neglected condition: https://www.unrealuk.org
} 
opposed to 'object-like' feelings in DPD). Crucially however, this complex and difficult process of navigating the multifaceted aspects of selfhood (from low-level bodily aspects to high level cognitive aspects), is tacitly - and one may say transparently - anchored in one's bodily experiences. Even when highly trained meditators manage to reach the 'purest' level of subjectivity and experience themselves as 'pure presence', (i.e. selfless and bodyless), basic bodily processing such as breathing tacitly and transparently sustains their subjectivity.

One may argue ${ }^{15}$ that depersonalisation-like states are inevitable steps on the challenging path towards self-exploration to the ultimate no-self or 'pure subjectivity' state targeted by Buddhist-based meditative practices. This remains an open question and further examination is needed in order to provide a systematic comparison between (i) meditation-induced forms of DPD, and (ii) trauma, drugs and anxiety induced forms of $\mathrm{DPD}^{16}$. For example, one key component seems to be the temporal dimension of self-experiences and its relation to the body in these cases. Specifically, in future work, it will be crucial to examine whether the feelings of being statically 'stuck' in the present, 'trapped' in one's head (mind) or lacking a narrative 'flow' or a 'plot' in one's life, as reported by the DPD patients even after more than 15 years of experiencing the condition (Ciaunica \& Charlton, 2018) are also characteristic of meditation-induced forms of DPD.

Observation of the similarity between some aspects of mediation and DPD symptomology may have important implications for potential therapy and interventions. Indeed, given that a typical DPD sufferer reports feelings of being 'trapped' in one's mind and disconnected from one's body and the world, we may be able to develop dynamic, body-based therapies, to counterbalance this mentalistic overscrutinization and self-objectifying stance. Moreover, while meditation-based interventions may prove useful in regulating the anxiety typically accompanying DPD experiences, they lack the key dynamic and embodied engagement component which would allow patients to override the static feelings of 'living in a bubble' or in one's head.

If our hypotheses presented here are correct, then it is by moving one's body - and which is more, by moving with others - that we can potentially dissolve the 'experiential airbag' that surrounds the fractured self in DPD, which feels isolated from the world (Ciaunica \& Fotopoulou, 2017). This recommendation is supported by anecdotical self-reports of DPD patients who often notice an improvement of their dissociation states after a period of intense physical training and/or social interactions: "a constant source of interaction is the only thing that allows me to maintain a connection with the world. I'll also seek physical contact with whoever I'm with. It almost feels as though I need to be that other person because my own sense of self is not strong enough in that moment to sustain me" (Jane C.). If this is so, then it is by reconnecting with the world via the others, that one may eventually learn to reconnect with oneself.

\footnotetext{
$\overline{15}$ We are grateful to an anonymous reviewer for clarification of this point.

${ }^{16}$ While there is evidence showing that meditative states involving a loss of the sense of self and body boundaries have long lasting positive effects on well-being (Austin, 2000; Dambrun, 2016), the idea that meditation necessarily leads to feelings of well-being may be misleading (Lindhal \& Britton, 2019). Indeed, self-exploratory practice may bring to the surface hidden distressing feelings or traumatic memories, and thereby trigger debilitating impairments with potentially irreversible consequences.
} 


\section{Conclusion}

In this paper we have considered altered forms of self-awareness in Depersonalization Disorder, which is a condition in which one feels detached from one's self, one's body and the world. Specifically, we have examined the experience of selfdetachment, which represents a 'divorce' or a 'fracture' between and observing and observed self. Building upon the phenomenological distinction between reflective and pre-reflective self-consciousness, and (a) the I- and body-as-subject and (b) the I- and body-as-object of an experience, our thesis is that DPD alters (1) the transparency of basic embodied forms of pre-reflective self-consciousness; (2) the capacity to flexibly modulate and switch between (a) and (b).

There is empirical evidence supporting the idea that impaired processing of bodily signals is characteristic of the condition. Our paper also draws on subjective first-personal reports, from individuals with DPD, supporting the idea of a dysfunctional processing of the link between the I- and body-as-subject and the Iand body-as-object of an experience. This split between and observing and observed self is also experienced in some Buddhist-derived meditative practices, implying that such techniques allow practioners to modulate the underlying and tacit transparency characterising the embodied and basic pre-reflective forms of self-consciousness.

Notably, the bodily roots of pre-reflective self-awareness continue to play a key role in sustaining - tacitly and 'transparently' -one's self-preservation, even when one consciously experiences one's self and one's body as being changed, 'dissolved' or even 'lost'.

Our key argument, therefore, is that alterations and changes in one's basic embodied pre-reflective sense of self can reveal its tacit and fundamental presence in our everyday experiences This is analogous to the way that cracks in otherwise transparent glass may indicate the presence of a previously unnoticed window. However, in the same way that whether the glass is cracked or clear doesn't make the window disappear, similarly modulating or disrupting the transparency of one's embodied sense of self doesn't make that disappear altogether, but rather it reappear sunder a different, modified form. DPD, we suggest is equivalent to living surrounded permanently by a cracked glass i.e. with a continuous disruption in the transparency of the sense of self.

Our novel characterisation suggests new directions for future research in pursuit of potential therapies to alleviate the distress of this little understood condition.

Open Access This article is licensed under a Creative Commons Attribution 4.0 International License, which permits use, sharing, adaptation, distribution and reproduction in any medium or format, as long as you give appropriate credit to the original author(s) and the source, provide a link to the Creative Commons licence, and indicate if changes were made. The images or other third party material in this article are included in the article's Creative Commons licence, unless indicated otherwise in a credit line to the material. If material is not included in the article's Creative Commons licence and your intended use is not permitted by statutory regulation or exceeds the permitted use, you will need to obtain permission directly from the copyright holder. To view a copy of this licence, visit http://creativecommons.org/licenses/by/4.0/. 


\section{References}

Albahari, M. (2010) Nirvana and Ownerless Consciousness, in Sidertis, M., Thompson, E., Zahavi, D. (2011) Editors. Self, No Self? Perspectives from Analytical, Phenomenological, and Indian Traditions. Oxford : Oxford University Press.

Ataria, Y., Dor-Ziderman, Y., \& Berkovich-Ohana, A. (2015 Dec). (2015). How does it feel to lack a sense of boundaries? A case study of a long-term mindfulness meditator. Consciousness and Cognition, 37, 133147.

Baker, D., Hunter, E., Lawrence, E., Medford, N., Patel, M., et al. (2003). Depersonalisation disorder: clinical features of 204 cases. British Journal of Psychiatry, 182, 428-433.

Billon, A. (2016). Making Sense of the Cotard Syndrome: Insights from the Study of Depersonalisation. Mind \& Language, 31, 356-391.

Billon, A. (2017a). Mineness First: three challenges to recent theories of the sense of bodily ownership. In A. Alsmith \& F. de Vignemont (Eds.), The Subject's Matter: Self-Consciousness and the Body. Cambridge MA: MIT Press.

Billon, A. (2017b) Basic Self-Awareness. European Journal of Philosophy 25 (3): 732-763. 2017.

Blanke, O., \& Metzinger, T. (2009). Full-body illusions and minimal phenomenal selfhood. Trends in Cognitive Sciences, 13, 7-13.

Cahn, B. R., \& Polich, J. (2006). Meditation states and traits: EEG, ERP, and neuroimaging studies. Psychological Bulletin, 132(2), 180-211.

Carhart-Harris, R. L., Erritzoe, D., Williams, T., Stone, J. M., Reed, L. J., Colasanti, A., et al. (2012). Neural correlates of the psychedelic state as determined by fMRI studies with psilocybin. Proceedings of the National Academy of Sciences of the United States of America, 109, 2138-2143.

Castillo, R. J. (1990 May). (1990). Depersonalisation and Meditation. Psychiatry., 53(2), 158-168.

Ciaunica, A. (2016). Basic Forms of Pre-reflective Self-Consciousness: a Developmental Perspective. In S. Miguens, G. Preyer, \& C. Morando (Eds.), Pre-reflective Self-Consciousness: Sartre and Contemporary Philosophy of Mind (pp. 422-438). London: Routledge.

Ciaunica, A., \& Fotopoulou, A. (2017). The Touched Self: Psychological and Philosophical Perspectives on Proximal Intersubjectivity and the Self. In C. Durt, T. Fuchs, \& C. Tewes (Eds.), Embodiment, Enaction, and Culture-Investigating the Constitution of the Shared World (pp. 173-192). Cambridge MA: MIT Press.

Ciaunica, A. (2019). The 'Meeting of Bodies': Empathy and Basic Forms of Shared Experiences. Topoi.

Ciaunica, A., Charlton, J. (2018). When the self slips: what depersonalization can say about the self https://aeon.co/essays/what-can-depersonalisation-disorder-say-about-the-self

Ciaunica, A., Crucianelli, L. (2019). Minimal Self-Awareness from Within - A Developmental Perspective. Journal of Consciousness Studies, Volume 26, Numbers 3-4, 2019, pp. 207- 226(20)

Colombetti, G., \& Ratcliffe, M. (2012). Bodily feeling in depersonalization: A phenomenological account. Emotion Review, 4(2), 145-150.

Compton, R. J., Banich, M. T., Mohanty, A., Milham, M. P., Herrington, J., Miller, G. A., Scalf, P. E., Webb, A., \& Heller, W. (2003). Paying attention to emotion: An fMRI investigation of cognitive and emotional Stroop tasks. Cognitive, Affective, \& Behavioral Neuroscience, 3(2), 81-96.

Crane, T., \& French, C. (2015). The Problem of Perception. In Stanford Encyclopaedia of Philosophy (Spring 2016 Edition) (Ed.), E N. Zalta Forthcoming URL http://plato.stanford.edu/archives/spr2016 /entries/perception-problem/.

Dahl, C. J., Lutz, A., \& Davidson, R. J. (2015). Reconstructing and deconstructing the self: Cognitive mechanisms in meditation practice. Trends in Cognitive Sciences, 19(9), 515-523.

Damasio, A. (2000). The Feeling of What Happens. Body, Emotion and the Making of Consciousness, London: Vintage.

Dambrun, M. (2016). When the dissolution of perceived body boundaries elicits happiness: The effect of selflessness induced by a body scan meditation. Consciousness and Cognition, 46, 89-98.

Daniels, J. K., Gaebler, M., Lamke, J. P., \& Walter, H. (2015). Grey matter alterations in patients with depersonalization disorder: A voxel-based morphometry study. Journal of Psychiatry and Neuroscience, 40(1), 19-27.

De Andrade, A. P. M., Amaro, E., Farhat, S. C. L., \& Schvartsman, C. (2016). Higher burnout scores in paediatric residents are associated with increased brain activity during attentional functional magnetic resonance imaging task. Acta Paediatrica, International Journal of Paediatrics, 105(6), 705-713. 
Dewe, H., Watson, D. G., Kessler, K., \& Braithwaite, J. J. (2018). The depersonalized brain: New evidence supporting a distinction between depersonalization and derealization from discrete patterns of autonomic suppression observed in a non-clinical sample. Consciousness and Cognition, 63, 29-46.

Dor-Ziderman, Y., Ataria, Y. Fulder, S., Goldstein, A., Berkovich-Ohana, A., (2016) Self-specific processing in the meditating brain: a MEG neurophenomenology study. Neuroscience of Consciousness 2016 (1)

de Jaegher, H., \& Di Paolo, E. (2007). Participatory sense-making: An enactive approach to social cognition. Phenomenology and the Cognitive Sciences, 6, 485-507.

Dugas, L. (1898). Un cas de dépersonnalisation. Revue Philosophique de la France et de l'Étranger, 45, 500507.

Farmer, H., \& Tsakiris, M. (2012). The bodily social self: A link between phenomenal and narrative selfhood. Review of Philosophy and Psychology, 3, 125-144.

Farmer, H., Cataldo, A., Adel, N., Wignall, E., Gallese, V., Deroy, O., Hamilton, A. F. de C., Ciaunica, A (submitted). The detached self: Investigating the effect of depersonalisation on self-bias in the visual remapping of touch.Psyarxiv, 1-34.

Fasching, W. (2008). Consciousness Self-Consciousness and Meditation. Phenom Cogn Sci, 7, 463.

Ferrè, E. R., \& Haggard, P. (2016). The vestibular body: Vestibular contributions to bodily representations. Cognitive Neuropsychology, 33(1-2), 67-81.

Fink, C. K. (2012) The 'Scent' of a Self: Buddhism and the First-Person Perspective, Asian Philosophy, 22:3, 289- 306, DOI:

Fotopoulou, A., \& Tsakiris, M. (2017). Mentalising Homeostasis. The Social Origins of Interoceptive Inference: replies to commentaries. The Neuropsychoanalysis Journal, 1-26.

Fuchs, T. (2005). Corporealized and disembodied minds. A phenomenological view of the body in melancholia and schizophrenia. Philosophy, Psychiatry, and Psychology, 12, 95-107.

Fuchs, T. (2015). From Self-Disorders to Ego Disorders. Psychopathology, 48, 324-331.

Gallagher, S. (2000). Philosophical conceptions of the self: implications for cognitive science. Trends in Cognitive Sciences, 4, 14-21.

Gallagher S, Zahavi D (2005) Phenomenological approaches to self-consciousness. Stanford encyclopedia of philosophy (http://plato.stanford.edu)

Garfield, J. L. (2015). Engaging Buddhism: Why it matters to philosophy. New York: Oxford University Press.

Gerrans, P. (2018). Depersonalisation Disorder Affective Processing and Predictive Coding. Review of Psychology and Philosophy.

Harman, G. (1990). The intrinsic quality of experience. Philosophical Perspectives, 4, 31-52.

Hohwy, J. (2014). The Self-evidencing Brain. Noûs, 48(1).

Hunter, E. C., Sierra, M., \& David, A. S. (2004). The epidemiology of depersonalization and derealisation . A systematic review. Society of Psychiatry Psychiatric Epidemiology, 3(9), 9-18.

Jáuregui Renaud, K. (2015). Vestibular function and depersonalization/derealization symptoms. Multisensory Research, 28(5-6), 637-651.

Kriegel, U. (2009). Subjective Consciousness: A Self-Representational Theory. Oxford: Oxford University Press.

Krueger, J. (2018). Schizophrenia and the Scaffolded Self. Topoi.

Legrand, D. (2006). The bodily self: The sensorimotor roots of pre-reflective self-consciousness. Phenomenology and the Cognitive Sciences, 5(1), 89-118.

Lemche, E., Brammer, M. J., David, A. S., Surguladze, S. A., Phillips, M. L., Sierra, M., Williams, S. C. R., \& Giampietro, V. P. (2013). Interoceptive-reflective regions differentiate alexithymia traits in depersonalization disorder. Psychiatry Research: Neuroimaging, 214(1), 66-72.

Lemche, E., Surguladze, S. A., Giampietro, V. P., Anilkumar, A., Brammer, M. J., Sierra, M., Chitnis, X., Williams, S. C. R., Gasston, D., Joraschky, P., David, A. S., \& Phillips, M. L. (2007). Limbic and prefrontal responses to facial emotion expressions in depersonalization. NeuroReport, 18(5), 473-477.

Lenggenhager, B., Tadi, T., Metzinger, T., \& Blanke, O. (2007). Video ergo sum: manipulating bodily selfconsciousness. Science, 317, 1096-1099. https://doi.org/10.1126/science.1143439.

Letheby, C., \& Gerrans, P. (2017). Self unbound: ego dissolution in psychedelic experience. Consciousn: Neurosci.

Lewis, M. (2003). The development of self-consciousness. In J. Roessler \& N. Eilan (Eds.), Agency and selfawareness (pp. 275-295). Oxford: Oxford University Press.

Limanowski, J., \& Friston, K. (2018). 'Seeing the dark': Grounding phenomenal transparency and opacity in precision estimation for active inference. Frontiers in Psychology, 9, 643. 
Lindahl, J. R., Fisher, N. E., Cooper, D. J., Rosen, R. K., \& Britton, W. B. (2017). The varieties of contemplative experience: A mixed-methods study of meditation- related challenges in Western Buddhists. PLoS One, 12, e0176239.

Lindahl, J. L., \& Britton, W. B. (2019). "I Have This Feeling of Not Really Being Here": Buddhist Meditation and Changes in Sense of Self. Journal of Consciousness Studies, 26(7-8), 157-183.

Longuenesse, B. (2017). I, Me. Mine: Oxford University Press.

Lutz, A., Slagter, H. A., Dunne, J. D., \& Davidson, R. J. (2008). Attention regulation and monitoring in meditation. Trends in cognitive sciences, 12(4), 163-169. https://doi.org/10.1016/j.tics.2008.01.005.

Medford, N., Sierra, M., Stringaris, A., Giampietro, V., Brammer, M. J., \& David, A. S. (2016). Emotional experience and awareness of self: Functional MRI studies of depersonalization disorder. Frontiers in Psychology, 7, 432.

Merleau-Ponty M (1945) Phénoménologie de la perception. Éditions Gallimard; English translation, Paris; Smith C (1962) Phenomenology of perception. Routledge and Kegan Paul, London

Metzinger, T. (2003). Phenomenal transparency and cognitive self-reference. Phenomenology and the Cognitive Sciences, 2, 353-393.

Michal, M., Wiltink, J., Subic-Wrana, C., Zwerenz, R., Tuin, I., Lichy, M., Brähler, E., \& Beutel, M. E. (2009). Prevalence, correlates, and predictors of depersonalization experiences in the German general population.The. Journal of Nervous and Mental Disease, 197(7), 499-506.

Millière R, Carhart-Harris R L., Roseman L, Trautwein F-M, Berkovich-Ohana A. (2018). Psychedelics, Meditation, and Self-Consciousness Front. Psychol., 04 September 2018

Nida-Rümelin, M. (2017). Self-awareness. Review of Philosophy and Psychology, 8, 55-82.

Owens, A. P., David, A. S., Low, D. A., Mathias, C. J., \& Sierra-Siegert, M. (2015). Abnormal cardiovascular sympathetic and parasympathetic responses to physical and emotional stimuli in depersonalization disorder. Frontiers in Neuroscience, 9, 89.

Panksepp, J. (1998). Affective Neuroscience: The Foundations of Human and Animal Emotions. Oxford/New York: Oxford University Press.

Parnas, J., \& Sass, L. A. (2001). Solipsism, self, and schizophrenic delusions. Philosophy, Psychiatry, and Psychology, 8, 101-120.

Rosenthal, D. (1997). A Theory of Consciousness. In Ned Block, Owen J. Flanagan \& Guven Guzeldere (eds.), The Nature of Consciousness. MIT Press (1997)

Sartre, J.-P. (1957). 1936. La transcendance de l'ego, Paris: Vrin; English translation: F. Williams and R. Kirkpatrick. The Transcendence of the Ego. New York: The Noonday Press.

Sass, L. A., \& Parnas, J. (2003). Schizophrenia, consciousness, and the self. Schizophrenia Bulletin, 29, 427444.

Sedlmeier, P., Eberth, J., Schwarz, M., Zimmermann, D., Haarig, F., Jaeger, S., \& Kunze, S. (2012). The psychological effects of meditation: A meta-analysis. Psychological Bulletin, 138(6), 1139-1171.

Seth, A. K., Suzuki, K., \& Critchley, H. D. (2012). An interoceptive predictive coding model of conscious presence. Frontiers in Psychology, 2, 395.

Seth, A., \& Tsakiris, M. (2018). Being a beast machine: The somatic basis of selfhood. Trends in Cognitive Sciences, 22(11), 969-981.

Sidertis, M., Thompson, E., Zahavi, D. (2011) Editors. Self, No Self? Perspectives from Analytical, Phenomenological, and Indian Traditions. Oxford : Oxford University Press.

Sierra, M., \& Berrios, G. E. (1998). Depersonalization: neurobiological perspectives. Biological Psychiatry, 44, 898-908.

Sierra, M. (2009). Depersonalisation: A New Look at a Neglected Syndrome. Cambridge: Cambridge University Press.

Sierra, M., Senior, C., Dalton, J., McDonough, M., Bond, A., Phillips, M. L., O’Dwyer, A. M., \& David, A. S. (2002). Autonomic response in depersonalization disorder. Archives of General Psychiatry, 59(9), 833838 .

Sierk, A., Daniels, J. K., Manthey, A., Kok, J. G., Leemans, A., Gaebler, M., Lamke, J. P., Kruschwitz, J., \& Walter, H. (2018). White matter network alterations in patients with depersonalization/derealization disorder.Journal of. Psychiatry and Neuroscience, 43(5), 347-357.

Simeon, D. (2006). Abugel J. Feeling Unreal: Depersonalization Disorder and the Loss of the Self. Oxford University Press.

Stanghellini, G. (2009). Embodiment and schizophrenia. World Psychiatry, 8, 56-59.

Strawson, G. (1999). The self and the SESMET. Journal of Consciousness Studies, 6, 99-135. 
Tibubos, A. N., Grammes, J., Beutel, M. E., Michal, M., Schmutzer, G., \& Brähler, E. (2017). Emotion regulation strategies moderate the relationship of fatigue with depersonalization and derealization symptoms. Journal of Affective Disorders, 227, 571-579.

Tye, M. (1999). Phenomenal consciousness: the explanatory gap as a cognitive illusion. Mind, 108, 705-725.

Thompson, E. (2006). Neurophenomenology and contemplative experience. In P. Clayton \& Z. Simpson (Eds.), The Oxford handbook of science and religion (p. 226235). New York, Oxford: Oxford University Press.

Vaitl, D., Birbaumer, N., Gruzelier, J., Jamieson, G. A., Kotchoubey, B., Kubler, A., et al. (2005). Psychobiology of altered states of consciousness. Psychological Bulletin, 131, 98-127.

Wozniak, M. (2018). "I" and "Me": The Self in the Context of Consciousness. Psychol: Front.

Zahavi, D. (2005). Subjectivity and Selfhood: Investigating the first-person perspective. Cambridge, MA: The MIT Press.

Zahavi, D. (2014) - Self and Other: Exploring Subjectivity, Empathy and Shame- Oxford: Oxford University Press.

Publisher's note Springer Nature remains neutral with regard to jurisdictional claims in published maps and institutional affiliations.

\section{Affiliations}

\section{Anna Ciaunica ${ }^{1,2} \cdot$ Jane Charlton ${ }^{3} \cdot$ Harry Farmer $^{4}$}

1 Institute of Philosophy, University of Porto, Via Panorâmica s, /n 4150-564 Porto, Portugal

2 Institute of Cognitive Neuroscience, University College London, Alexandra House, Queen Square London WC1N 3AR, the, London, UK

3 UNREAL, The, London, UK

4 Department of Psychology, University of Bath, Bath, England 